\title{
MarXiv Summary
}

MarXiv: The free research repository for the ocean \& marine-climate sciences

\section{Conservation targets might be reducing trust in MPA planning}

Surveys of northern California-based fishermen indicate that there is a relationship between the trust fishermen have in groups like managers and researchers, and their satisfaction with the outcomes of an MPA planning process. Low levels of trust with managers were tied to low levels of satisfaction with the MPA planning process. Conservation targets may be an impediment for building that trust.

The authors conducted interviews with 178 commercial fisherman and charter-fishing operators to assess their perceptions of the implementation of California's North Coast MPA network. The network was fully implemented in 2012, with interviews conducted in 2014. This research sought to answer three questions, which we'll address in order:

\section{What are fishermen's perceptions of the process through which the North Coast MPA network was implemented and, in particular, efforts to incorporate local participation?}

Fishermen reported that they decided to unify themselves and present a joint proposal, rather than participate in an individual manner, after watching other California MPA processes unfold. The fishermen viewed their joint proposal as instrumental in ensuring the new MPAs did not disrupt their fishing activities. However, despite this belief, fishermen felt the process was very top-down and only tried to make them feel as though they were involved, rather than truly involving them. One fisherman noted, "When we participate, most of the time they don't believe anything we say." More than four-out-of-five respondents were very dissatisfied, dissatisfied, or simply neutral with the overall planning process. Slightly better satisfaction was reported for efforts at including local input.

\section{What are fishermen's perceptions of the potential impacts or outcomes from the implementation of the MPA network?}

Two-thirds of respondents disagreed or strongly disagreed that the North Coast MPA network will improve overall ocean health. The majority also felt that the network would not improve their net fishing income. These sentiments likely stem from the fact that the fishermen were able to place the MPAs in relatively unused fishing areas, thus not affecting heavily-fished sites. Recovery to overfished stocks is, therefore, unlikely to occur because of the new spatial closures.

\section{What factors might be driving fishermen's perceptions of the MPA network?}

A belief that the MPAs were placed in (largely) unfished waters happened in-spite of the planning process, rather than because of the process, could be one driver. The authors write:

"When the group [of fishermen] came up with a unified proposal that limited impacts to fishermen and deviated from science guidelines - [Marine Life Protection Act] decisionmakers were not able to weigh competing visions. They essentially had no choice but to
This is a summary of: It's a trust thing: Assessing fishermen's perceptions of the California North Coast marine protected area network

Accessible at: https://marxiv.org/7a2c9

Authors: Lucia OrdoñezGauger, Laurie Richmond, Steven Hackett, Cheryl Chen

Added to MarXiv: April 2018

Published: Ocean \& Coastal Management, 2018

Suggested Citation: Conservation targets might be reducing trust in MPA planning. OCTO (2018). DOI: $10.17605 / O S F$. IO/7DA4T

See more MarXiv summaries at https://www.marxivinfo.org/ summaries

Share your research in MarXiv and the MarXiv Team may summarize it, just like this!

Step-by-step instructions on how to share your research in MarXiv are detailed at https://www.marxivinfo.org/ submission

Across all disciplines, papers available for free with a preprint (also known as "Green OA") are cited $30 \%$ more than the world average (DOI: 10.7287/peerj. preprints.3119v1) 


\section{MarXiv Summary}

MarXiv: The free research repository for the ocean \& marine-climate sciences

accept that proposal, which they did with a few small modifications. Although fishermen may have ended up with a good outcome, many did not perceive that outcome as a result of how the planning process was designed. Rather they saw it as emerging from the community coming together to co-opt the process and make it work for them."

Another possible driver: conservation targets. Some fishermen noted that the MPA process didn't seem to be designed to address any specific needs, but was rather started simply to achieve conservation targets.

Trust, or lack thereof, could also have an effect. The authors surveyed respondents using a 1-5 Likert scale to determine which groups party to the process they trusted. Fishermen were neutral (3.39) with regard to trusting other fishermen, and no group was trusted more than this. Researchers were in second place with a score of 3.2. The California Ocean Protection Council and the Marine Life Protection Act Initiative were both the least trusted groups with scores of 1.78 and 1.93, respectively. Statistically-significant relationships were observed between fishers' trust levels with the Marine Life Protection Act Initiative, and their satisfaction with both the MPA process and locations of MPA sites. There was also a significant relationship between a fisher's satisfaction with the MPA process and satisfaction with the MPA locations. The finding that trust and satisfaction are intertwined may explain why satisfaction was so low, despite a positive outcome for the fishers.

A key takeaway from the authors: "Targets or timelines for global MPA coverage can contribute a sense of urgency that may be antithetical to the trust-building that is necessary to ensure MPAs enjoy long-term social success and acceptability."

The MarXiv Team

Nick Wehner,

Director of Open Initiatives, OCTO

Raye Evrard,

Project Manager, ОСТO

Allie Brown,

Project Associate, ОСТO

Sarah Carr,

Chief Knowledge Broker,

OCTO

John Davis,

President, OCTO

Correspondence

Nick Wehner

nick@octogroup.org

Financial support for MarXiv comes from the David and Lucile Packard Foundation.

The views expressed herein are those of the MarXiv

Team and should not be interpreted as representing the opinions or policies of the Packard Foundation or other funders of MarXiv.

Join the MarXiv Summaries monthly newsletter at https:// oct.to/marxivsum

MarXiv is an ОСТO Initiative
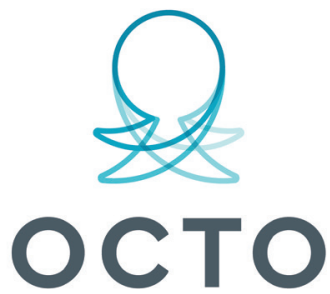

OPEN COMMUNICATIONS FOR THE OCEAN 